\title{
Oral administration of interferon- $\alpha 2 b$-transformed Bifidobacterium longum protects BALB/c mice against coxsackievirus B3-induced myocarditis
}

\author{
Zhijian Yu', Zhen Huang ${ }^{1}$, Chongwen Shao ${ }^{2}$, Yuanjian Huang ${ }^{2}$, Fan Zhang ${ }^{1}$, Jin Yang ${ }^{1}$, Lili Deng ${ }^{1}$, \\ Zhongming Zeng ${ }^{1}$, Qiwen Deng ${ }^{1 *}$ and Weiseng Zeng ${ }^{2}$
}

\begin{abstract}
Multiple reports have claimed that low-dose orally administered interferon (IFN)- $\alpha$ is beneficial in the treatment of many infectious diseases and provides a viable alternative to high-dose intramuscular treatment. However, research is needed on how to express IFN stably in the gut. Bifidobacterium may be a suitable carrier for human gene expression and secretion in the intestinal tract for the treatment of gastrointestinal diseases. We reported previously that Bifidobacterium longum can be used as a novel oral delivery of IFN- $\alpha$. IFN-transformed $B$. longum can exert an immunostimulatory role in mice; however the answer to whether this recombinant B. longum can be used to treat virus infection still remains elusive. Here, we investigated the efficacy of IFN-transformed B. longum administered orally on coxsackie virus B3 (CVB3)-induced myocarditis in BALB/C mice. Our data indicated that oral administration of IFN-transformed B. longum for 2 weeks after virus infection reduced significantly the severity of virus-induced myocarditis, markedly down regulated virus titers in the heart, and induced a T helper 1 cell pattern in the spleen and heart compared with controls. Oral administration of the IFN-transformed B. longum, therefore, may play a potential role in the treatment of CVB3-induced myocarditis.
\end{abstract}

Keywords: Bifidobacterium, Coxsackievirus B, Enterovirus, Interferon, Myocarditis, Oral administration

\section{Introduction}

The oral use of low doses of interferon (IFN)- $\alpha$ has been shown to exhibit beneficial effects in mice or human with acquired immunodeficiency syndrome (AIDS) [1], hepatitis B [2], aphthous stomatitis [3], and measles [4]. These studies have indicated that IFN- $\alpha /-\beta$ given orally provides a viable alternative to the current high-dose treatment intramuscularly [5,6]. The number of dairy and probiotic products that contain bifidobacteria has developed rapidly in recent years, and its probiotic properties have been extended further by the production of the recombinant Bifidobacterium-containing products [7-11]. Genetically engineered Bifidobacterium has been reported as a successful exogenous gene delivery carrier for the treatment of many diseases. We previously constructed a recombinant $B$. longum (IFNtransformed $B$. longum) that was inducible by arabinose to express efficiently secreted IFN- $\alpha 2 b$ in vitro [12]. Moreover, oral administration of IFN-transformed $B$. longum to mice increased intestinal SIgA and serum IFN- $\alpha 2 b$ levels, which suggested the potential clinical value of this bacterium as a kind of oral interferon in the treatment of virus infection [13].

Human IFN can inhibit coxsackievirus B3 (CVB3) replication in vitro and protects murine models from CVB3-induced myocarditis [14-19]. However, it is not clear whether oral administration of IFN can treat CVB3-induced myocarditis in vivo. In this study, the effect of IFN-transformed B. longum by oral administration on the development of CVB3-induced myocarditis in mice was evaluated.

\footnotetext{
* Correspondence: qiwendeng@hotmail.com

'Department of Infectious Diseases, the Affiliated Shenzhen Nanshan Hospital of Guangdong Medical College, No 89, Taoyuan Road, Nanshan district, 518052 Shenzhen, China

Full list of author information is available at the end of the article
}

(c) 2011 Yu et al.; licensee BioMed Central Ltd. This is an Open Access article distributed under the terms of the Creative Commons Attribution License (http://creativecommons.org/licenses/by/2.0), which permits unrestricted use, distribution, and reproduction in any medium, provided the original work is properly cited. 


\section{Materials and methods Cells and viruses}

CVB3 (Nancy strain) was obtained from Prof. Wang at the Department of Biotechnology of Ginan University, China [20]. African green monkey kidney (Vero) cells were cultured in Dulbecco's modified Eagle's medium (DMEM) that contained 8\% fetal calf serum (Gibco, Rockville, USA). Confluent cultures of Vero cells were infected with CVB3 and incubated at $37^{\circ} \mathrm{C}$ until an extensive cytopathic effect was observed (generally at 35 days post-infection). Subsequently, the culture media were collected, the cell debris was pelleted by centrifugation and removed and the supernatant was aliquoted and stored at $-80^{\circ} \mathrm{C}$.

\section{Bacteria culture}

IFN-transformed $B$. longum were constructed by transforming B. longum with pBAD-SPIFN (BSPIFN) as reported [12]. Briefly, BSPIFN plasmids consisted of a fusion gene of the arabinosidase signal peptide and human IFN- $\alpha 2 \mathrm{~b}$ (hIFN $\alpha 2 \mathrm{~b}$ ). Recombinant IFN-transformed $B$. longum contained an $\mathrm{L}$-arabinose promoter and displayed highly efficient IFN- $\alpha 2 b$ expression [12]. The control plasmid-transformed B. longum bacteria were transformed with the control plasmid (pBADgIIIA) without the insertion of hIFN- $\alpha 2 b$ gene. Recombinant BSPIFN- and control plasmid-transformed $B$. longum were cultured anaerobically and prepared as described in our previous report [12]. A 10- $\mu$ l suspension of bacteria was seeded onto BL agar plates (Nissui) that contained $100 \mathrm{~g} \mathrm{~L}^{-1}$ ampicillin to determine the actual number of viable bacilli in the inocula. Colonies were counted after $24 \mathrm{~h}$ of anaerobic culture.

\section{Interventions and groups}

This study was approved by the Ethics Committee of Southern Medical University (Guangzhou, China). Fourweek-old male BALB/c mice (weight, $15 \pm 0.5$ g; Southern Medical University, USA) were inoculated i.p. with a $50 \%$ cell-culture infectious dose of CVB3 at $5 \times 10^{6}$ (as determined by plaque assay on Vero cells). Infected animals given this virus dosage survived for at least 6 months post-infection. We studied the efficacy of IFNtransformed B. longum on coxsackievirus B3-induced myocarditis. Forty BALB/c mice were inoculated with the virus and were divided into four groups. 'BIFN' group and 'Control' group animals were administered orally with IFN- and control plasmid- transformed $B$. longum for 2 weeks respectively after the inoculation of the virus. The 'IFN' group was injected i.m. with a therapeutic dose $\left(1.5 \mu \mathrm{g} \mathrm{kg}^{-1}\right.$ week $\left.^{-1}\right)$ of pegylated IFN $\alpha 2 \mathrm{~b}$ (PegIntron). The 'saline' group was administered i.p. once daily with sterile saline after infection. Three mice were kept under the same conditions to act as the normal control. Recombinant bacteria were given to the mice orally once every 2 days using a tuberculin syringe attached to a 20 -gauge olive-tip steel feeding tube, passed through the oral cavity and esophagus. All animals were killed at day 14 post-infection (following ether anesthesia). Up to day 14 post-infection, half of the murine hearts were dissected aseptically for virus titration and RNA extraction for cytokine quantity. The other half of the heart was used for hematoxylin-eosin (H\&E) staining. The spleen was removed surgically to isolate mononuclear cells (MNCs).

\section{Morphometry}

Hematoxylin-eosin staining was performed according to the standard techniques. The selected surfaces of myocarditis lesions studied were considered to be representative of the relative inflammatory area in the entire heart volume, because of the relatively homogeneous distribution of the myocarditis lesions in the affected hearts. The number of myocarditis lesions and their surface proportion were determined with $\mathrm{H} \& \mathrm{E}$-stained sections of the hearts of the untreated and other groups. The proportion of the surface occupied by myocarditis lesions was determined by means of a conventional point-counting method, as reported earlier [21], by using an ocular grid that contained 121 equally spaced points. The surface proportion was taken to be an estimate of the percentage of heart tissue that was affected by focal myocarditis. Counting was performed on three sections per heart and the sections were evaluated at a magnification of less than $\times 200$.

\section{Virus titration from heart homogenate}

The aseptic hearts of the animals were weighed and homogenized in the minimal essential medium of $2 \mathrm{ml}$ phosphate-buffered saline (PBS). The supernatant was subjected to three freeze-thaw cycles and centrifugation at $5000 \mathrm{rpm}$ for $8 \mathrm{~min}$, then was absorbed and diluted sequentially 10-fold in RPMI 1640 medium. Vero cells were grown to confluence in microtiter trays, infected with serial dilutions of the homogenates, and incubated for $3 \mathrm{~h}$ at $37^{\circ} \mathrm{C}$. The cells were cultured for $72 \mathrm{~h}$ of cultivate, then the monolayers were fixed in $10 \%$ phosphate-buffered formalin and stained with crystal violet (Invitrogen); the numbers of plaques were counted. Virus titers were determined by standard plaque formation assay and expressed as per organ weight (in grams).

\section{Quantitation of transcript level of cytokines and Mx1}

The total RNA of the heart tissues was extracted with Trizol reagent (Invitrogen, Carlsbad, CA, USA) and reverse transcribed into $\mathrm{cDNA}$ according to the 
manufacturer's protocol (Invitrogen, Carlsbad, CA, USA). Transcription of IFN- $\gamma$, TNF- $\alpha, \mathrm{Mx} 1$ or the housekeeping gene $\beta$-actin was detected by real-time polymerase chain reaction (PCR) using a SYBR Green Master Mix (Applied Biosystems). Thermocycler conditions included an initial denaturation step at $94^{\circ} \mathrm{C}$ for 2 min; a three-step cycle procedure was carried out (denaturation, $94^{\circ} \mathrm{C}, 20 \mathrm{~s}$; annealing, $58^{\circ} \mathrm{C}, 20 \mathrm{~s}$; and extension, $\left.72^{\circ} \mathrm{C}, 30 \mathrm{~s}\right)$ for 35 cycles. All reactions were performed in at least duplicate for each sample. Data were collected and analyzed quantitatively on an ABI Prism 7900 sequence detection system (Applied Biosystems). The $\beta$-actin gene was used as an endogenous control to normalize for differences in the amount of total RNA in each sample and the relative mRNA expression was calculate by normalization to the value of the $\beta$-actin transcripts. Primers for IFN- $\gamma$, TNF- $\alpha$, Mx1 and the housekeeping gene $\beta$-actin have been reported previously $[13,21]$.

\section{Preparation of mononuclear cells (MNCs) and cytokine detection}

Spleens were removed surgically, and the MNCs were isolated as described previously [22]. Suspensions of MNCs from the spleen were prepared with RPMI-1640 culture medium that contained heat-inactivated fetal bovine serum $\left(50 \mathrm{~mL} \mathrm{~L}^{-1}\right)$, L-glutamine $(2 \mathrm{mM})$, penicillin $(1 \times$ $\left.10^{5} \mathrm{U} \mathrm{L}^{-1}\right)$, streptomycin $\left(100 \mathrm{mg} \mathrm{L}^{-1}\right)$, and HEPES (25 $\mathrm{mM}$ ) (all from Life Sciences). The MNCs were seeded into 24-well plates (each well had $2 \times 10^{8}$ cells $\mathrm{L}^{-1}$ ) and stimulated subsequently with $100 \mu \mathrm{L}$ of Con $\mathrm{A}\left(5 \mathrm{mg} \mathrm{L}^{-1}\right)$ for 72 h at $37^{\circ} \mathrm{C}, 5 \% \mathrm{CO}_{2}$ in air, and $95 \%$ humidity. The levels of IFN- $\gamma$, TNF- $\alpha$ and IL-10 in the supernatants were measured by OptEIA commercial enzyme-linked immunosorbent assay (ELISA) kits (BD Pharmingen), following the manufacturers' instructions. The detection limits of the ELISA assays were as follows: $2500 \mathrm{pg} \mathrm{ml}^{-1}$ for IFN- $\gamma, 825$ $\mathrm{pg} \mathrm{ml}^{-1}$ for TNF- $\alpha$ and $650 \mathrm{pg} \mathrm{ml}^{-1}$ for IL-10.

\section{Statistical analysis}

Data were shown as the mean \pm standard error of the mean (SEM). Statistical analyses of the data were performed by one-way analysis of variance (ANOVA), and the correlation between two variables was tested by bivariate correlation analysis using SPSS11.0; a $p$-value < 0.01 was considered to be statistically significant.

\section{Results}

Evaluations for the severity of myocarditis and virus replication

The prominent cardiac inflammation area is observed in Figure 1. The percentage of the pathological area of the heart sections in the BIFN, B, IFN- $\alpha$ and saline groups was elevated and is compared in Figure 2a. The pathological area of heart sections in the BIFN group was significantly lower compared with the $\mathrm{B}$ and saline groups $(p<0.01)$ respectively, but markedly high compared with the IFN group. The levels of cardiac CVB3 titers and CVB3 RNA in the cardiac tissues of the BIFN group were significantly lower compared with the $\mathrm{B}$ and saline groups respectively and markedly higher compared with IFN group $(p<0.01)$ (Figure $2 b)$.
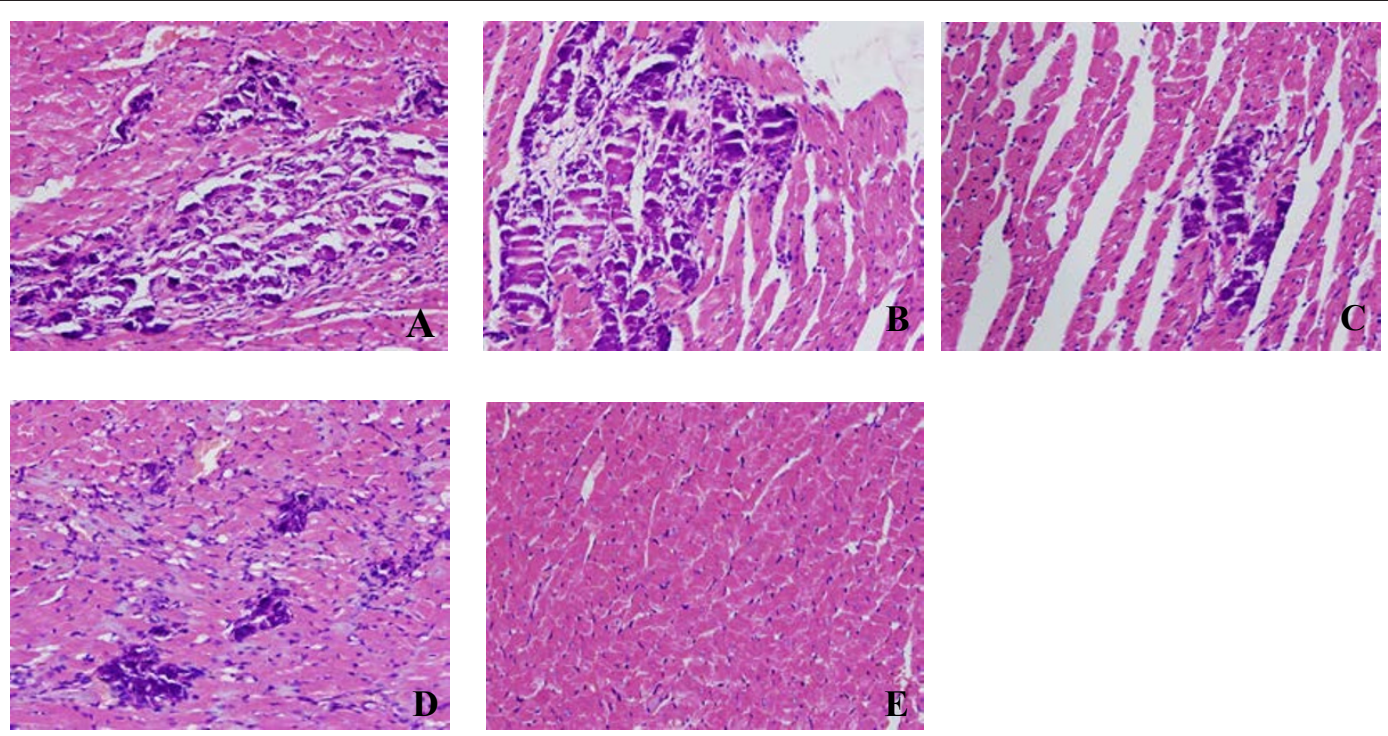

Figure 1 Evaluation of the severity of myocarditis. (a-e) are representative of histopathologic images in heart tissue from saline, B, BIFN and interferon (IFN) groups respectively (hemotoxylin and eosin (H\&E) staining, original magnification $\times 200$ ). Ten mice per group were analyzed in this study. 

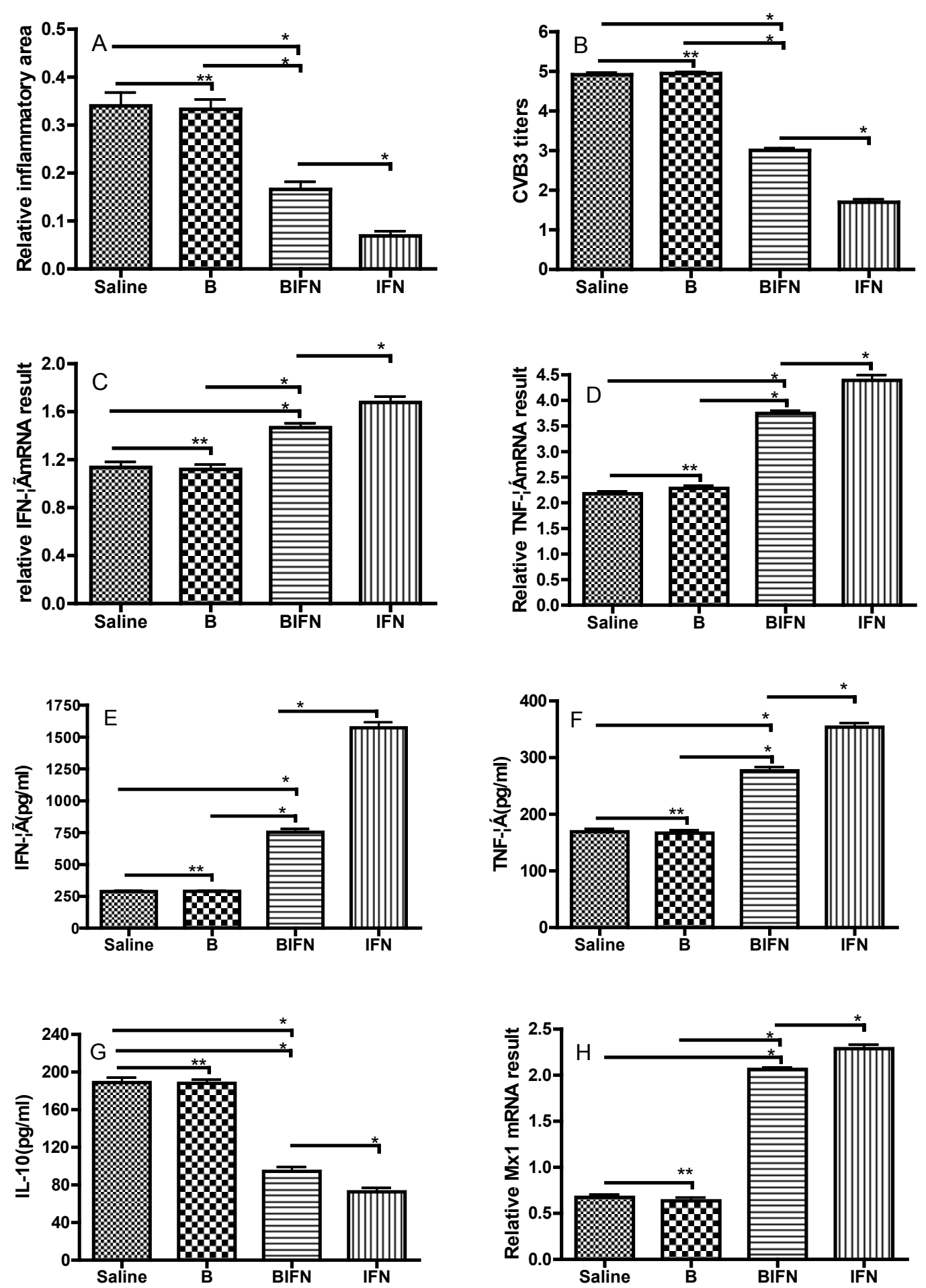

Figure 2 Pathological areas of the heart. The percentage of pathological areas in different groups was shown in (a). The coxsackievirus B3 (CVB3) titration detected by standard plaque formation assay was indicated in (b). The levels of interferon (IFN)- $\gamma$ and tumor necrosis factor (TNF)- $\alpha$ mRNA were determined in (c) and (d) respectively. The concentration of, IFN- $\gamma$ and TNF- $\alpha$ and were shown in (e, $\mathbf{f}$ and $\mathbf{g}$ ) respectively. The detection of IFN-induced Mx1 mRNA was determined in (h). ${ }^{* *}$ versus B group, $p>0.05$; ${ }^{*}$ versus BIFN group, $p<0.01$. 


\section{Enhanced levels of IFN- $\gamma$ and TNF- $\alpha$}

We evaluated the T helper (Th) cell patterns induced by oral-administered IFN-transformed $B$. longum by measurement of the levels of two typical Th1 cytokines (IFN- $\gamma$ and TNF- $\alpha$ ). Our data showed that the cardiac IFN- $\gamma$ and TNF- $\alpha$ mRNA levels in the BIFN group were enhanced significantly compared with that in the saline and B groups but were markedly reduced compared with that in the IFN- $\alpha$ group ( $p<0.01$; Figure $2 \mathrm{c}, \mathrm{d})$. Furthermore, we detected the levels of IFN- $\gamma$, TNF- $\alpha$ and IL-10 in the supernatant from the cultured MNCs from murine spleen. The levels of supernatant IFN- $\gamma$ and TNF- $\alpha$ in the BIFN group were markedly raised compared with that in the saline and $\mathrm{B}$ groups $(p<$ $0.01)$. Moreover, the levels of serum IL-10 in BIFN group were also markedly decreased compared with that in the saline and B groups ( $p<0.01$; Figure $2 \mathrm{~g})$.

\section{Increased expression of Mx1 mRNA in cardiac tissues}

The Mx1 gene is induced typically by IFN. Its intracellular gene transcription level in a tissue samples can represent the relative amount of local type I IFN that stimulates the cells or tissues [23,24]. We measured the $M x 1$ gene transcription levels in cardiac tissues using real-time PCR to evaluate the local type I IFN concentration and activity. High Mx1 mRNA transcript levels were detected in the BIFN group compared with the saline and B groups respectively ( $p<0.01$; Figure $2 \mathrm{~h}$ ), a finding that was suggestive of a possibly high type I IFN concentration in this organ.

\section{Discussion}

In this experiment, we proved the efficacy of the BIFNtransformed B. longum cells on the CVB3-induced myocarditis. Oral administration of IFN-transformed $B$. longum cells can reduce significantly the cardiac inflammatory area of CVB3-infected mice by day 14 compared with the $B$ and saline groups respectively, which suggested that BIFN-transformed B. longum cells can improve the severity of disease. It has been demonstrated that the dominant pathogenic process in the early stages of CVB3 infection is the direct attack on myocardial cells by the virus, therefore antivirus treatment at this phase is very important to improve the development of virus infection [25]. Our data indicated that the cardiac virus titers in the murine heart of BIFN group were decreased significantly compared with B group, which indicated that this recombinant B. longum may improve cardiac inflammation partly by inhibition of virus replication at the early stage of CVB3 infection. Classical theories suggest that CD $4^{+}$Th1 cells play a vital role against virus infection in adaptive immune responses by production of IFN- $\gamma$ for effective clearance of virus invasion. In this study, IFN-transformed B. longum increased the expression of Th1 cytokines (IFN- $\gamma$ and TNF- $\alpha$ ) mRNA in cardiac tissue and enhanced the secretion of Th1 cytokines (IFN- $\gamma$ and TNF- $\alpha$ ) from splenocytes, which suggested that this recombinant $B$. longum is able to induce expression of $\mathrm{CD} 4^{+}$Th1 cells against virus infection.

Our former studies have shown that hIFN- $\alpha 2 \mathrm{~b}$ from IFN-transformed B. longum is expressed mainly as a mature secretory cytokine and that serum hIFN- $\alpha 2 b$ level can be enhanced in the mice that have been administrated orally with $B$. longum $[12,13]$. As we know, the expression of hIFN- $\alpha 2 \mathrm{~b}$ in IFN-transformed $B$. longum is mainly induced by L-arabinose, which is a component of biopolymers such as hemicellulose and pectin [26]. The administration of IFN-transformed B. longum has been demonstrated to increase the serum and intestinal IFN$\alpha 2 \mathrm{~b}$ level and we hypothesize that IFN expression by this bifidobacteria in mice might be induced persistently by L-arabinose in MRS or by the administered food and then enter the blood circulation by gastrointestinal absorption [13]. In this study, we compared mice either treated with saline and control B. longum mice respectively. The Mx1 mRNA levels, which represent the local tissue IFN concentration, were increased significantly in cardiac tissues in the BIFN group, which suggested that IFN-transformed B. longum can increase the level of active type 1 IFN locally. Further study is needed to ascertain how to control the expression of IFN stably in gut and whether these bacteria affect the microbial flora.

Bifidobacterium has many beneficial effects on human health that include prevention of infection, immunomodulation, promotion of lactose digestion and protection against colon cancer [9-11]. Recently, genetically engineered Bifidobacterium has been used successfully as an exogenous gene delivery carrier for bowel disease and cancer gene therapy [9-11,27]. This finding suggests that Bifidobacterium may be a suitable carrier for human gene expression and secretion in the intestinal tract for the treatment of gastrointestinal diseases. Here, we demonstrated the efficacy of BIFN-transformed $B$. longum to CVB3-induced myocarditis in the mice. Our data showed, compared with IFN-transformed $B$. longum, that IFN- $\alpha 2 \mathrm{~b}$ administered intramuscularly could reduce significantly virus infection, decrease the severity of virus-induced myocarditis, and induce a robust Th1 pattern in the spleen and heart. Nevertheless, IFN-transformed B. longum has its own advantages that include localization in the gastrointestinal cavity and spread of the physiological role locally [13]. Further experimentation is needed to evaluate whether IFNtransformed B. longum can be added to probiotic yogurt or diet and whether it can protect high-risk people who eat these products from the virus myocarditis. The model in this study was to inoculate with CVB3 intraperitoneally and this route may affect the therapeutic efficacy of IFN-transformed B. longum compared with 
IFN- $\alpha 2 b$ given intramuscularly. The preventive or therapeutic roles of IFN-transformed B. longum in virus diseases need to be studied further.

In conclusion, oral administration of IFN-transformed $B$. longum can decrease the severity of virus-induced myocarditis, reduce the virus titers in the heart and induce a Th1 pattern in the spleen and heart in vivo. IFN-transformed B. longum may play a potential role in the treatment of coxsackie virus B3-induced myocarditis. However, the advantages of the IFN-transformed $B$. longum in the treatment and prevention of enterovirus infection need to be studied further.

\section{Acknowledgements}

This work was supported by two grants from Shenzhen scientific Research Program of the People's Republic of China (NO. 200801020 and NO. 201001023) and Science and Technology Planning Project of Guangdong Province, China (No. 2010B011000005).

\section{Author details}

'Department of Infectious Diseases, the Affiliated Shenzhen Nanshan Hospital of Guangdong Medical College, No 89, Taoyuan Road, Nanshan district, 518052 Shenzhen, China. ${ }^{2}$ Department of Cell Biology, Southern Medical University, No 1023, Satai Raod, Baiyun district, 510515 Guangzhou, China.

\section{Authors' contributions}

$\mathrm{QD}$ and WZ conceived the study and QD wrote the paper. ZY, ZH, CS, YH, $F Z, J Y, L D$ and WZ participated in the laboratory studies. All authors read and approved the final manuscript.

\section{Competing interests}

The authors declare that they have no competing interests.

Received: 22 July 2011 Accepted: 8 December 2011

Published: 8 December 2011

\section{References}

1. Katabira ET, Sewankambo NK, Mugerwa RD, Belsey EM, Mubiru FX, Othieno C, Kataaha P, Karam M, Youle M, Perriens JH, Lange JM: Lack of efficacy of low dose oral interferon alfa in symptomatic HIV-1 infection: a randomised, double blind, placebo controlled trial. Sex Transm Infect 1998, 74(4):265-270.

2. Cummins J, Beilharz M, Krakowka S: Oral use of interferon. J Interferon Cytokine Res 1999, 19:853-857.

3. Hutchinson VA, Mok WL, Angenend JL, Cummins JM, Richards AB: Chronic major aphthous stomatitis: oral treatment with low-dose alphainterferon. Mol Biother 1990, 2(4):217-220.

4. Lecciones JA, Abejar NJ, Dimaano EE, Bartolome R, Cinco S, Mariano N, Yerro ME, Cobar S, Fuggan B: A pilot double-blind, randomized, and placebo-controlled study of orally administered IFN-a-n1 (Ins) in pediatric patients with measles. J Interferon Cytokine Res 1998, 18:647-652.

5. Kim Y, Thapa M, Hua DH, Chang KO: Biodegradable nanogels for oral delivery of interferon for norovirus infection. Antiviral Res 2011, 89(2):165-173.

6. Dec M, Puchalski A: Use of oromucosally administered interferon-alpha in the prevention and treatment of animal diseases. Pol J Vet Sci 2008, 11:175-186.

7. Hu B, Kou L, Li C, Zhu LP, Fan YR, Wu ZW, Wang JJ, Xu GX: Bifidobacterium longum as a delivery system of TRAIL and endostatin cooperates with chemotherapeutic drugs to inhibit hypoxic tumor growth. Cancer Gene Ther 2009, 16:655-663.

8. Reyes Escogido ML, De León Rodríguez A, Barba de la Rosa AP: A novel binary expression vector for production of human IL-10 in Escherichia coli and Bifidobacterium longum. Biotechnol Lett 2007, 29:1249-1253.

9. Shkoporov AN, Efimov BA, Khokhlova EV, Kafarskaia LI, Smeianov W: Production of human basic fibroblast growth factor (FGF-2) in
Bifidobacterium breve using a series of novel expression/secretion vectors. Biotechnol Lett 2008, 30:1983-1988.

10. Tang W, He Y, Zhou S, Ma Y, Liu G: A novel Bifidobacterium infantismediated TK/GCV suicide gene therapy system exhibits antitumor activity in a rat model of bladder cancer. J Exp Clin Cancer Res 2009, 28:155.

11. Yazawa K, Fujimori M, Nakamura T, Sasaki T, Amano J, Kano Y, Taniguchi S: Bifidobacterium longum as a delivery system for gene therapy of chemically induced rat mammary tumors. Breast Cancer Res Treat 2001, 66:165-170.

12. Deng Q, Zeng W, Yu Z: Signal peptide of Arabinosidase enhances secretion of interferon-alpha2b protein by Bifidobacterium longum. Arch Microbiol 2009, 191:681-686.

13. Yu Z, Zeng Z, Huang Z, Lian J, Yang J, Deng Q, Zeng W: Increased mRNA expression of interferon-induced $M \times 1$ and immunomodulation following oral administration of IFN- $\mathrm{a} 2 \mathrm{~b}$-transformed $B$. longum to mice. Arch Microbiol 2010, 192:633-638.

14. Heim A, Grumbach I, Pring-Akerblom P, Stille-Siegener M, Muller G, Kandolf R, Figulla HR: Inhibition of coxsackievirus B3 carrier state infection of cultured human myocardial fibroblasts by ribavirin and human natural interferon-alpha. Antivir Res 1997, 34:101-111.

15. Kandolf $\mathrm{R}$, Canu A, Hofschneider PH: Coxsackie B3 virus can replicate in cultured human fetal heart cells and is inhibited by interferon. $J \mathrm{Mol}$ Cell Cardiol 1985, 17:167-181.

16. Okada I, Matsumori A, Matoba Y, Tominaga M, Yamada T, Kawai C: Combination treatment with ribavirin and interferon for coxsackievirus B3 replication. J Lab Clin Med 1992, 120:569-573.

17. Padalko E, Nuyens D, De Palma A, Verbeken E, Aerts JL, De Clercq E, Carmeliet $\mathrm{P}$, Neyts J: The interferon inducer ampligen [poly(I)-poly(C12U)] markedly protects mice against coxsackie B3 virus-induced myocarditis. Antimicrob Agents Chemother 2004, 48(1):267-274.

18. Deonarain R, Cerullo D, Fuse K, Liu PP, Fish EN: Protective role for interferon-beta in coxsackievirus B3 infection. Circulation 2004, 110:3540-3543

19. Wang YX, da Cunha V, Vincelette J, White K, Velichko S, Xu YF, Gross C, Fitch RM, Halks-Miller M, Larsen BR: Antiviral and myocyte protective effects of murine interferon-beta and -alpha2 in coxsackievirus B3induced myocarditis and epicarditis in BALB/c mice. Am J Physiol Heart Circ Physiol 2007, 293:H69-H76.

20. Wang YF, Wang XY, Ren Z, Qian CW, Li YC, Kaio K, Wang QD, Zhang Y, Zheng LY, Jiang JH, Yang CR, Liu Q, Zhang YJ: Phyllaemblicin B inhibits coxsackie virus B3 induced apoptosis and myocarditis. Antiviral Res 2009, 84(2):150-158.

21. Yuan J, Yu M, Lin QW, Cao AL, Yu X, Dong JH, Wang JP, Zhang JH, Wang M, Guo HP, Cheng X, Liao YH: Th17 cells contribute to viral replication in coxsackievirus B3-induced acute viral myocarditis. $J$ Immunol 2010, 185(7):4004-4010.

22. Alignani D, Maletto B, Liscovsky M, Rópolo A, Morón G, PistoresiPalencia MC: Orally administered OVA/CpG-ODN induces specific mucosal and systemic immune response in young and aged mice. $J$ Leukocyte Biol 2005, 77:898-905.

23. Bollati-Fogolín M, Müller W: Virus free, cell-based assay for the quantification of murine type I interferons. I Immunol Methods 2005, 306:169-175.

24. Petry H, Cashion L, Szymanski P, Ast O, Orme A, Gross C, Bauzon M, Brooks A, Schaefer C, Gibson H, Qian H, Rubanyi GM, Harkins RN: Mx1 and IP-10: biomarkers to measure IFNbeta activity in mice following genebased delivery. J Interferon Cytokine Res 2006, 26:699-705.

25. Dennert R, Crijns HJ, Heymans S: Acute viral myocarditis. Eur Heart J 2008, 29:2073-2082.

26. David RL: CRC Handbook of Chemistry and Physics. 88 edition. Boca Raton: CRC Press; 2007, 110

27. Yao J, Wang JY, Lai MG, Li YX, Zhu HM, Shi RY, Mo J, Xun AY, Jia CH, Feng JL, Wang LS, Zeng WS, Liu L: Treatment of mice with dextran sulfate sodium-induced colitis with human interleukin 10 secreted by transformed Bifidobacterium longum. Mol Pharm 2011, 8(2):488-497.

doi:10.1186/1743-422X-8-525

Cite this article as: Yu et al:: Oral administration of interferon- $\alpha 2 b$ transformed Bifidobacterium longum protects $B A L B / C$ mice against coxsackievirus B3-induced myocarditis. Virology Journal 2011 8:525. 